\title{
Test and Research on Dynamic Characteristics of A Mega-frame Model Structure under Ambient Vibration
}

\author{
Sasa HE \\ Civil and Architecture College \\ Central South University \\ Changsha, China \\ e-mail: csuhs@126.com
}

\author{
Zhiwu YU \\ Civil and Architecture College \\ Central South University \\ Changsha, China \\ e-mail: zhwyu@ mail.csu.edu.cn
}

\begin{abstract}
The dynamic characteristics of a mega-frame model structure under ambient vibration was tested and analyzed. The article compared two methods of modal parameter identification: the Ibrahim Time Domain Technique (ITD) in time domain, and the Fast Fourier Transform (FFT) in frequency domain. Then verified the similar relation by checking the test analysis results on the calculation results of the original structure.
\end{abstract}

Keywords-component; mega-frame; ambient vibration; dynamic characteristics; modal parameter identification

\section{TEST}

\section{A. Introduction}

The 1/10 reduced-scale model structure of 21 floors was ready for dynamic characteristics test. Pulsating method has been chosen to gain the frequencies and modes of structure for the laboratory equipment limitation. The structure diagram shows in Figure 1.
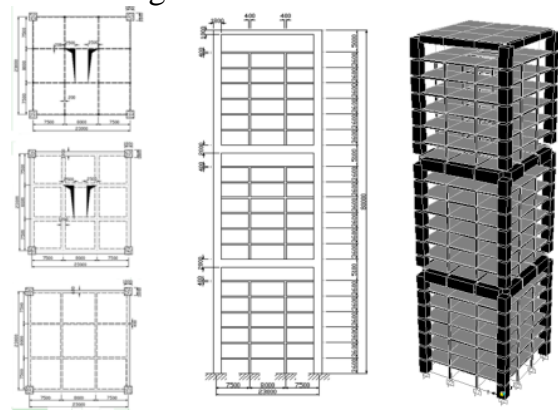

Figure 1. Structure diagram

\section{B. Instruments and Equipment}

The instruments used in this test are listed in TABLE I.

TABLE I. INSTRUMENTS AND EQUIPMENT

\begin{tabular}{|l|c|}
\hline \multicolumn{1}{|c|}{ Instruments } & Number \\
\hline 891-II Vibration sensor & 3 \\
\hline 891Charge voltage filter integrated amplifier & 1 \\
\hline IMC Data acquisition system & 1 \\
\hline
\end{tabular}

\section{Measuring Point Arrangement}

The test is mainly to measure the horizontal vibration and torsional vibration of the model structure. In measuring the horizontal vibration, the sensor is generally arranged in the center of stiffness of the building, the purpose is to let the sensor receives only the horizontal vibration signal. In measuring the torsional vibration of the building, the measuring point is generally arranged on both sides of the building in order to get the torsional vibration signal [1]. The test reference point is selected at the top of the roof. The sensor was bonded on the floor by adhesive $\mathrm{AB}$.

Position arrangement of measuring points and sampling frequency are shown in 0 . Due to the limited number of sensors, sensor H4246\# placed on top floor as the reference point. In order to measure the vibration shape, sensor H4247\#, H4246\# moved from the 1st floor to the 19th floor with an interval of 1 floor as the measured points.

TABLE II. MEASURING POINTS ARRANGEMENT AND SAMPLING FREQUENCY

\begin{tabular}{|c|c|c|c|c|c|}
\hline \multirow{2}{*}{ Case } & Reference & \multicolumn{2}{|c|}{ Measure points } & \multicolumn{2}{c|}{ Frequency } \\
\cline { 2 - 6 } & H4246\# & H4247\# & H4248\# & $\begin{array}{c}\text { Samplin } \\
\text { g }\end{array}$ & $\begin{array}{c}\text { Cut- } \\
\text { off }\end{array}$ \\
\hline $\begin{array}{c}\text { South- } \\
\text { North } \\
\text { (S-N) }\end{array}$ & $\begin{array}{c}\text { SN;21 } \\
\text { center }\end{array}$ & $\begin{array}{c}\text { SN;1,5,9, } \\
13,17 \\
\text { center }\end{array}$ & $\begin{array}{c}\text { SN;3,7,11,1 } \\
5,19 \\
\text { center }\end{array}$ & $20 \mathrm{HZ}$ & \\
\hline $\begin{array}{c}\text { East- } \\
\text { West } \\
\text { (E-W) }\end{array}$ & $\begin{array}{c}\text { EW;21 } \\
\text { center }\end{array}$ & $\begin{array}{c}\text { EW;1,5,9, } \\
13,17 \\
\text { center }\end{array}$ & $\begin{array}{c}\text { EW;3,7,11, } \\
15,19 \\
\text { center }\end{array}$ & $100 \mathrm{~Hz}$ & $20 \mathrm{~Hz}$ \\
\hline $\begin{array}{c}\text { Torsion } \\
(\mathrm{T})\end{array}$ & $\begin{array}{c}\text { EW;21 } \\
\text { center }\end{array}$ & $\begin{array}{c}\text { NE;1,5,9, } \\
13,17 \\
\mathrm{NE} \text { corner }\end{array}$ & $\begin{array}{c}\text { NE;3,7,11, } \\
15,19 \\
\text { NE corner }\end{array}$ & $100 \mathrm{~Hz}$ & $20 \mathrm{~Hz}$ \\
\hline
\end{tabular}

\section{IDENTIFICATION OF MODAL PARAMETERS IN TIME DOMAIN}

\section{A. Data Checking}

We need to check the stability, normality, and periodicity of the Sample data while testing and after analysising the sample data [2].

It is necessary to recollection the dample data if there is a large fluctuation. To check on the stability of the sample data, take the 17th floor north-south waveform (Figure 2) as an example, we can see that the signal has no obvious fluctuation, peak valley changes relatively uniform. 
The probability density function of the sampled data (Figure 3) is analyzed, and the shape of the data is consistent with the theory.

From the time domain signal of the test South-North waveform, as showed in Figure 4, it can be concluded that the whole record is similar to the "beat" phenomenon, which reflects the frequency characteristics of the structure to a certain extent.

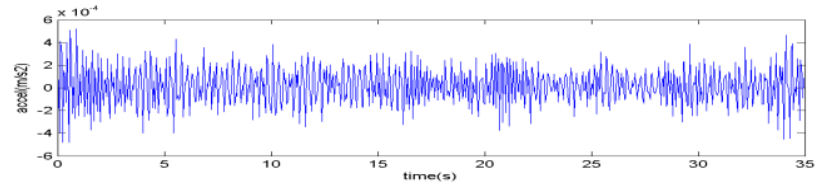

Figure 2. The 17th floor south-north waveform in time domain

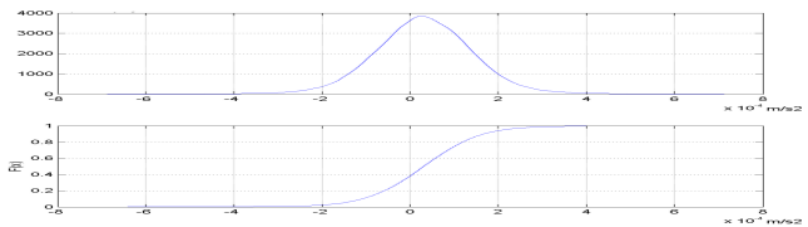

Figure 3. Probability density and probability distribution function

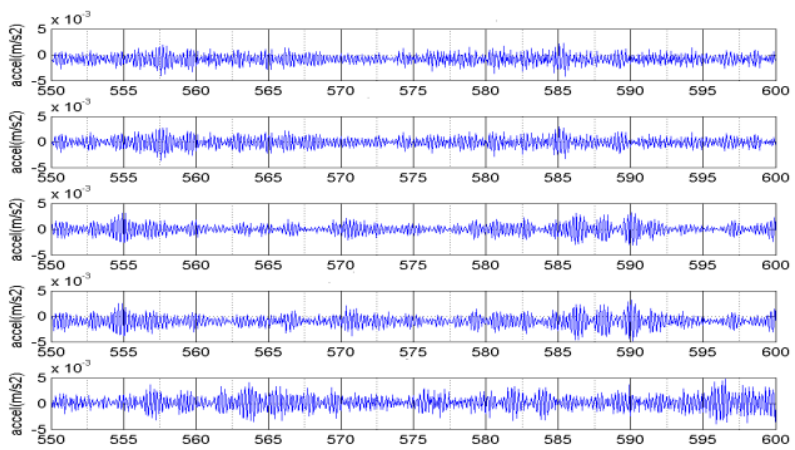

Figure 4. The 11, 13,15, 17, 19 floor south-north waveform in time domain

B. Castration and Smooth Preconditioning of the Timedomain Signal
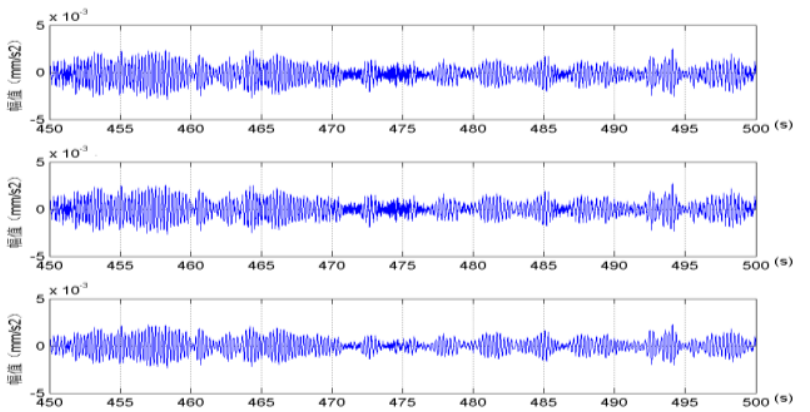

Figure 5. The sample signal, trend elimination signal and smoothed signal of 15 th floor under torsion condition

In this paper, the sampling frequency of $20 \mathrm{~Hz}$, carry on the elimination of the trend pretreatment only. The sampling frequency of $50 \mathrm{~Hz}$ and $100 \mathrm{~Hz}$, add the data smoothing pretreatment. Figure 5. has shown the 15th floor sample signal under torsion condition, compared

with the signal after eliminating trend and smoothing processing results. It is visible that through eliminating polynomial trend, the signal departures from the baseline after 480s, has been corrected. And through 'five point moving average', the signal between 470 s and 480 s has been smoothed.

\section{Random Decrement Technique Pretreatment}

Random decrement method is a kind of data preprocessing method for white noise excitation, that extracting free vibration signal from the vibration response signal [3]. Figure 6. shows the results of pretreatment by using the method of random decrement.

\section{Ibrahim Time Domain Technique}

The Ibrahim Time Domain Technique (ITD) was proposed by S. R. Ibrahim in the 1970s [4]. It is a method for identification of modal parameters by using time domain signal of free vibration response of structure, such as displacement, velocity and acceleration. Based on the theory that the free damped response of a linear multi degree system with viscous damping can be expressed as a combination of various modes. Take sample of the free response signal at 3 different time-delays, and construct the free attenuation response data matrix, then solve the eigenvalue problem of the mathematical model, obtain modal parameters of the system. Figure 7. shows the results of ITD curve fitting under South-North condition. The corresponding numerical results are listed in TABLE III.

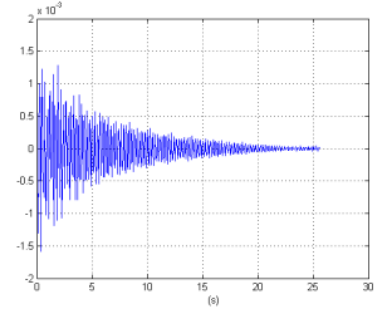

Figure 6. Pretreatment with random decrement method (southnorth, $\mathrm{N}=512$ )

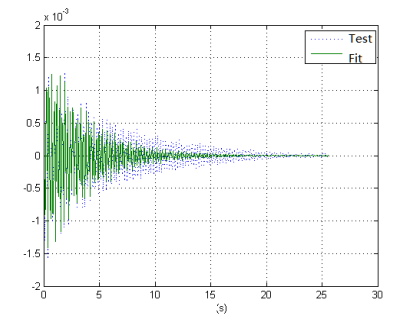

Figure 7. Results of ITD curve fitting (south-north, $\mathrm{N}=512$ )

TABLE III. NUMERICAL RESUlTS OF ITD CURVE FITTING

\begin{tabular}{|c|c|c|c|}
\hline Case & frequency (Hz) & damping ratio (\%) & coefficient \\
\hline \multirow{3}{*}{$\begin{array}{c}\text { South- } \\
\text { North } \\
\mathrm{mn}=4\end{array}$} & 3.80 & 10.20 & 0.000176 \\
\cline { 2 - 4 } & 4.20 & 1.36 & 0.000057 \\
\hline \multirow{3}{*}{$\begin{array}{c}\text { East- } \\
\text { West } \\
\mathrm{mn}=12\end{array}$} & 6.88 & 1.02 & 0.000048 \\
\cline { 2 - 4 } & 3.71 & 1.03 & 0.000013 \\
\cline { 2 - 4 } & 4.17 & 7.36 & 0.000034 \\
\cline { 2 - 4 } & 6.50 & 17.93 & -0.000047 \\
\hline \multirow{2}{*}{$\begin{array}{c}\text { Torsion } \\
\mathrm{mn}=12\end{array}$} & 13.44 & 2.31 & 0.000018 \\
\cline { 2 - 4 } & 19.41 & 2.68 & 0.000015 \\
\cline { 2 - 4 } & 3.72 & 1.15 & -0.000028 \\
\hline \multirow{2}{*}{} & 4.18 & 3.35 & 0.000028 \\
\hline
\end{tabular}




\section{IDENTIFICATION OF MODAL PARAMETERS IN FREQUENCY DOMAIN}

\section{A. FFT Transform}

Frequency spectrum analysis and power spectrum analysis are the common methods used to analyze the pulse signal. Frequency spectrum analysis also known as Fourier analysis, which is a process that decomposing the complex signal into the superposition of several sinusoidal signals. The Fast Fourier Transform (FFT) was proposed by Cooley and Turkey in 1964. FFT take advantage of the relationship between the triangle functions of the time domain signal to simplify the iterative calculation. It is very fast for the spectrum analysis of data sequence with the sample number of $2^{n}$. The signal can be divided into a number of time domain blocks for FFT analysis, generally divided into 25 30 signal groups, calculate in each time domain block, then average the values of signal groups to keep the accuracy of the experiment. Take 512 or 1024 as the data number of each time block in this article.

Figure 8. and Figure 9. show the frequency spectrum and power spectrum of test points on the top floor under different cases. From which we can see the peak points are clear and easy to distinguish, which indicates that there is a strong periodic component in the test data.
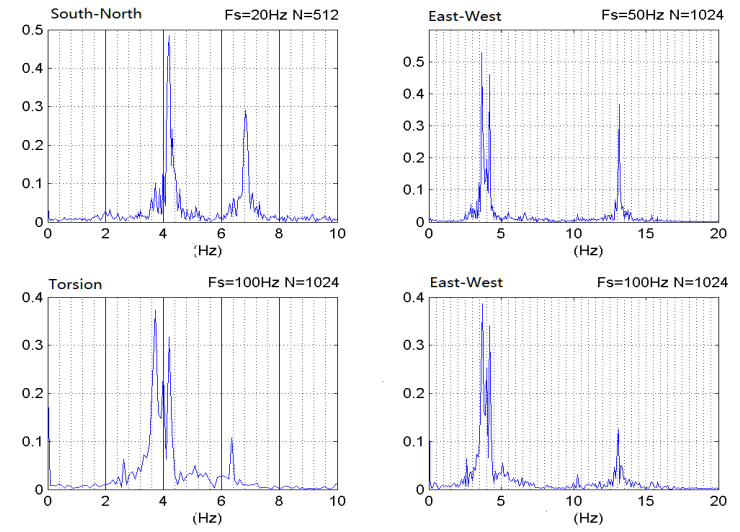

Figure 8. Frequency spectrum of test points on top floor
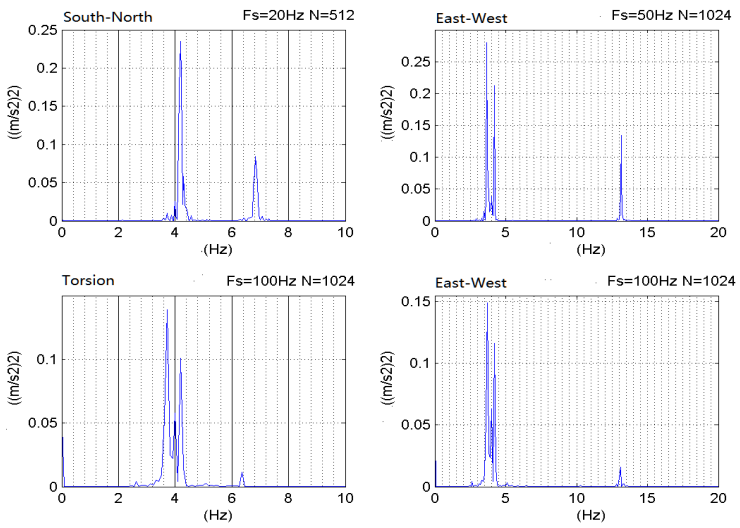

Figure 9. Power spectrum of test points on top floor

Phase angle cannot be ignored in FFT analysis. After applying FFT transform of the time domain data, on natural

frequencies, the coherence function between the output signal of 2 test points will be close to 1, phase angle will be close to 0 degree (horizontal vibration) or 180 degree (torsional vibration). Figure 10. shows the function amplitude, phase angle and coherence coefficient between test points on $19^{\text {th }}$ floor and $21^{\text {th }}$ floor under South-North case.
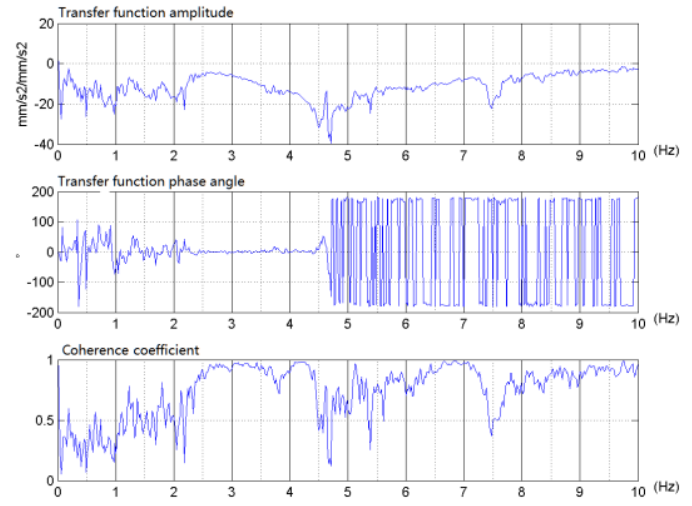

Figure 10. The transform function amplitude, phase angle and coherence coefficient between test points on 19th floor and 21th floor under southnorth case

\section{B. Mode Frequencies and Mode Shapes}

The natural frequencies can be obtained by the ratio of the response different test points at the natural frequencies. Take the reference point on top floor as the input, other measure points as output, the modal shape can be obtained by the transfer function between the input and output and the cross spectrum analysis.

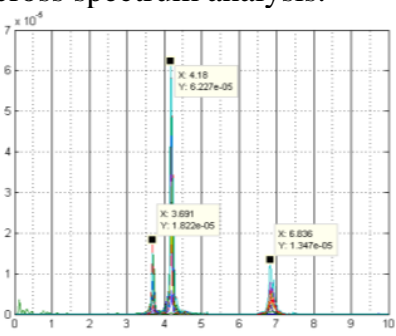

Figure 11. Power spectrum under south-north case $(\mathrm{S}-\mathrm{N})$

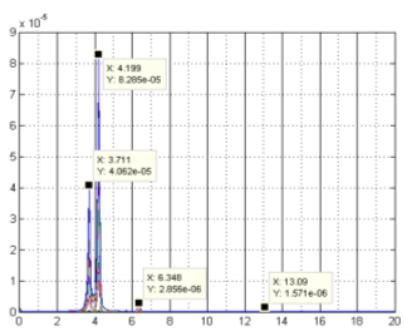

Figure 13. Power spectrum under torsion case $(\mathrm{T})$

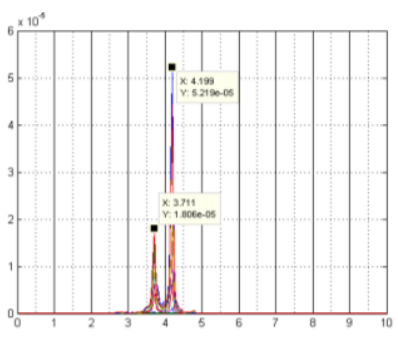

Figure 12. Power spectrum under east-west case (e-w)

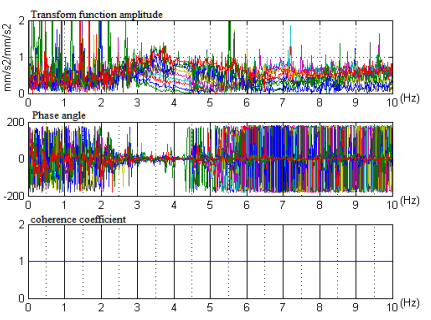

Figure 14. Amplitude, phase and coherence coefficient (S-N) 


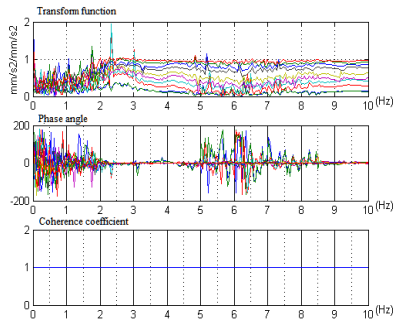

Figure 15. Amplitude, phase and coherence coefficient (E-W)

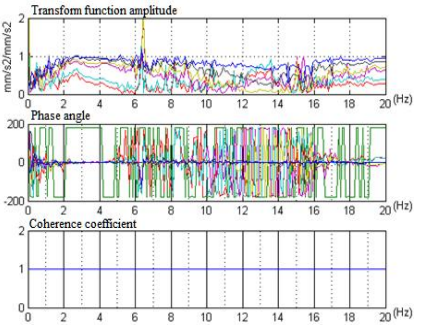

Figure 16. Amplitude, phase and coherence coefficient (T)

Figure 11. Figure 13. show the power spectrum of all measure points under different cases. Figure 14. Figure 16. show the transform function amplitude, phase angle and coherence coefficient of all measure points under different cases.

The natural frequency obtained by the spectrum analysis method list in TABLE IV. The mode figure of vibration shows in Figure 17. Figure 19. [4].

TABLE IV. NATURAL FREQUENCY By SPECTRUM ANALYSIS

\begin{tabular}{|c|c|c|c|c|}
\hline \multirow{2}{*}{ Case } & \multicolumn{4}{|c|}{ Frequency } \\
\cline { 2 - 5 } & $\boldsymbol{f}_{\boldsymbol{1}}$ & $\boldsymbol{f}_{\boldsymbol{2}}$ & $\boldsymbol{f}_{\boldsymbol{3}}$ & $\boldsymbol{f}_{\boldsymbol{4}}$ \\
\hline $\mathrm{S}-\mathrm{N}$ & 3.69 & 4.18 & 6.84 & \\
\hline $\mathrm{E}-\mathrm{W}$ & 3.71 & 4.20 & & 13.13 \\
\hline $\mathrm{T}$ & 3.71 & 4.20 & 6.35 & 13.08 \\
\hline
\end{tabular}

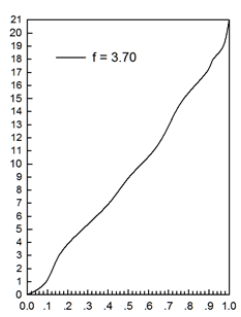

Figure 17. 1st order horizontal vibration mode (south-north)

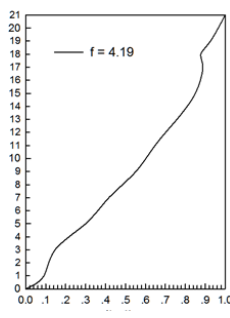

Figure 18. 1st order horizontal vibration mode (east-west)

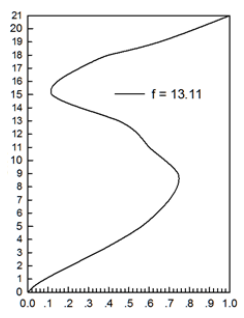
horizontal vibration mode (east-west)
Figure 19. 2nd order

\section{Similarity Ratio BetweEn the TeSt Results AND THE PROTOTYPE STRUCTURE}

Similarity ratios between the frequency results of test model structure in both time domain and frequency domain, and the calculation results of actual structure, are listed in TABLE V. \& TABLE VI. Modal Identification Result Comparement between time domain and frequency domain list in OSimilarity ratio approach 10.
TABLE V. SIMILARITY RATIOS (ITD)

\begin{tabular}{|c|c|c|c|c|c|}
\hline Case & $\mathbf{f}_{\mathbf{1}}(\mathbf{S}-\mathbf{N})$ & $\mathbf{f}_{\mathbf{1}}(\mathbf{E}-\mathbf{W})$ & $\mathbf{f}_{\mathbf{2}}(\mathbf{E}-\mathbf{W})$ & $\mathbf{f}_{\mathbf{1}}(\mathbf{T})$ & $\mathbf{f}_{\mathbf{2}}(\mathbf{T})$ \\
\hline Test & 3.74 & 4.18 & 12.99 & 6.4 & 19.41 \\
\hline Actual & 0.432 & 0.432 & 1.283 & 0.623 & 1.819 \\
\hline Ratios & 8.7 & 9.7 & 10.1 & 10.4 & 10.7 \\
\hline Error & $13 \%$ & $3 \%$ & $1 \%$ & $4 \%$ & $7 \%$ \\
\hline
\end{tabular}

TABLE VI. SimILARITY RATIOS (SPECTRUM ANALYSIS)

\begin{tabular}{|c|c|c|c|c|}
\hline Case & $\mathbf{f}_{\mathbf{1}}(\mathbf{S}-\mathbf{N})$ & $\mathbf{f}_{\mathbf{1}}(\mathbf{E}-\mathbf{W})$ & $\mathbf{f}_{\mathbf{2}}(\mathbf{E}-\mathbf{W})$ & $\mathbf{f}_{\mathbf{1}}(\mathbf{T})$ \\
\hline Test & 3.7 & 4.19 & 13.11 & 6.6 \\
\hline Actual & 0.432 & 0.432 & 1.283 & 0.623 \\
\hline Ratios & 8.6 & 9.7 & 10.6 & 10.2 \\
\hline Error & $14 \%$ & $3 \%$ & $6 \%$ & $2 \%$ \\
\hline
\end{tabular}

TABLE VII. MODAL IDENTIFICATION RESULT COMPAREMENT BETWEEN TIME DOMAIN AND FREQUENCY DOMAIN

\begin{tabular}{|c|c|c|c|c|}
\hline Case & $\mathbf{f}_{\mathbf{1}}(\mathbf{S}-\mathbf{N})$ & $\mathbf{f}_{\mathbf{1}}(\mathbf{E}-\mathbf{W})$ & $\mathbf{f}_{\mathbf{2}}(\mathbf{E}-\mathbf{W})$ & $\mathbf{f}_{\mathbf{1}}(\mathbf{T})$ \\
\hline ITD & 3.74 & 4.18 & 12.99 & 6.4 \\
\hline Spectrum & 3.7 & 4.19 & 13.11 & 6.6 \\
\hline Error & $1.08 \%$ & $0.24 \%$ & $0.92 \%$ & $3.03 \%$ \\
\hline
\end{tabular}

\section{CONCLUSION}

Through the test of the dynamic characteristics of the structure, the natural frequency and the vibration mode function curve are obtained, which provide accurate dynamic parameters for the seismic analysis of the structure.

The modal parameters are identified by the analysis of time domain and frequency domain respectively. The results obtained are consistent and the error is very small. Compared with the calculation results of the prototype structure with the finite element program analysis, the similarity ratio is basically in accordance with the law of similarity.

The measured frequencies of the two principal axes are not exactly the same. The error may caused by the size of the model base plate, which has different size between SouthNorth direction and East-West direction.

\section{ACKNOWLEDGMENT}

This project is based on "The seismic performance and dynamic reliability analysis of the mega frame structure, supported by the National Natural Science Foundation of China, (50478092)".

\section{REFERENCES}

[1] ZHOU Yang, SHI Wei-xing, "Vibration Test and analysis of the fundamental periodic of multi-story masonry structures with largebay", in Magnetism, vol.29 No.11, pp. 197-204. Nov 2012.

[2] Wang Ji. Application of MATLAB in vibration signal processing, 1st ed, Beijing: 2006, pp. 69-73.

[3] Li Guoqiang., and Li Jie, Theory and application of dynamic testing of engineering structures, 1st ed, Beijing: 2002, pp .40-42.

[4] Chen Ying, "Testing and Analysis of Dynamic Characteristics of a M asonry S tructure of Multistorey Building", in Magnetism, vol.132 No.6, pp. 39-44. Nov 2012. 